\title{
A Mixed Integer Programming Model for Supplier Selection and Order Allocation Problem with Fuzzy Multiobjective
}

\author{
Hongtao Hu, Haotian Xiong, Yuanfeng You, and Wei Yan \\ Logistics Engineering College, Shanghai Maritime University, Shanghai, China \\ Correspondence should be addressed to Yuanfeng You; ivan.u@foxmail.com
}

Received 22 October 2016; Accepted 16 November 2016

Academic Editor: Si Zhang

Copyright (C) 2016 Hongtao Hu et al. This is an open access article distributed under the Creative Commons Attribution License, which permits unrestricted use, distribution, and reproduction in any medium, provided the original work is properly cited.

\begin{abstract}
A mixed integer programming model is proposed to solve supplier selection and order allocation problem for a manufacturer. In this model, quality, delivery performance, and purchasing cost are chosen as three criteria to select suppliers and set as objectives. Inventory level, goods flow balance, service level, supply ability, and marketing demand are considered as constraints. In the proposed model, the three objectives have different weights which are given by experts. However, the experts score the weight by many subjective factors. So, the fuzzy analytic hierarchy process (FAHP) based approach is used to calculate the weighted values. In the end, a case study illustrates the advantage of weighted values solved by FAHP. And the result shows that a weighted model is more advantageous for supplier selection and order allocation.
\end{abstract}

\section{Introduction}

Suppliers and manufacturers play an important role in the supply chain network. The procurement between them affects the downstream of the supply chain. Reasonable purchasing price and good quality of raw materials can reduce manufacturing cost. And then distributors and retailers can get the product from upstream with reduced wholesale price. Finally, customers can be benefited. What is more, reasonable price and good quality of the product can enlarge the demand, which benefits the entire supply chain. Obviously, supplier selection and order allocation are critical.

We consider the procurement between a manufacturer and suppliers in two aspects, supplier selection and order allocation. For supplier selection, Dickson [1] and Weber et al. [2] made some researches in the criteria for supplier selection, and they ranked the importance for each criterion. According to the researches of Dickson and Weber et al., quality, delivery performance, and purchasing cost are regarded as the criteria for supplier selection. And rejected items from the supplier are used to reflect quality, and late delivery items are used to reflect delivery performance. Purchasing cost involves inventory cost, cooperative cost, and wholesale cost. These three criteria have relevance with each other, so a multiobjective function is formulated to solve supplier selection problem in this paper.

As for order allocation, a decision variable is set for purchasing quantity. We can obtain corresponding order allocation after solving supplier selection problem. To make the result more reasonable, besides customer's demand, inventory level, and supply ability as constraints, a minimum order quantity is required for manufactures. Furthermore, rejected items and late delivery items are taken into consideration in goods flow, which makes the multiobjective function more reasonable for supplier selection and order allocation in real life situation.

The innovation of this paper is to use fuzzy analytic hierarchy process (FAHP) which was proposed by Zadeh [3] in 1965. The weights of three objectives are calculated by FAHP in proposed MIP model. And we apply the weighted values into an innovative model to solve supplier selection and order allocation problem. The reason why FAHP is used to solve the weighted values is that different manufacturers give different importance to these criteria. For example, manufacturers not only focus on the cost of fresh product, but also focus more on the quality. So, these criteria should be given a weighted value to reflect their importance. Furthermore, these criteria are scored by experts subjectively. So, FAHP is used to improve 
this problem. Compared to conventional AHP, FAHP is a better method to avoid uncertainties as many as possible.

The rest of this paper is organized as follows. Section 2 is the literature review about supplier selection and order allocation. In Section 3, we introduce the index, parameters, and decision variables. Then the multiobjective function is formulated for supplier selection. Section 4 introduces some approaches to solve supplier selection. And we propose some steps to solve this problem. Section 5 uses a case study to illustrate the advantage of weighted values solved by FAHP, and two results solved by single Crisp Formulation and a weighted model are compared in Section 6. Finally, Section 7 is the conclusion.

\section{Literature Review}

For supplier selection, two scholars made some important researches. Dickson [1] started to research it in 1966 by raising questionnaires to 273 procurement managers and agents, and 170 valid responses were received. Afterwards, 23 criteria were summarized to evaluate a supplier. According to this summary, Dickson analyzed these 23 criteria and these 23 criteria were ranked in terms of importance. Another scholar, Weber et al. [2], systematically concluded 74 literatures published from 1967 to 1990 about supplier selection and these 23 criteria were ranked again [4]. The importance ranked by Dickson expressed more views from the perspective of procurement managers and agents while Weber's views expressed some scholars' thoughts [5]. It was noticeable that purchasing cost, delivery performance, and quality were all ranked to top three by both Dickson and Weber et al. Based on these fundamental papers, many scholars published some articles about optimal approaches or decisions such as Zhen [6] in 2015 and Dong et al. [7] in 2010.

As for the methods to solve supplier selection problem, scholars like Kumar et al. (2005) [8] applied fuzzy sets to formulate a model solving the Multiobjective Integer Programming Vendor Selection Problem (MIP_VSP), minimizing the purchasing cost, net late delivery items, and net rejected items. Kumar et al. (2008) [9] used AHP and fuzzy linearprogramming to solve supplier selection with minimum cost. Lee (2009) [10] ranked suppliers in accordance with profit, marketing opportunity, cost, and risk, then selecting suppliers by Fuzzy AHP. Kokangul and Susuz (2009) [11] used AHP and nonlinear programming to formulate an objective function to maximize TVP (Total Value of Procurement) and minimize TCP (Total Cost of Procurement), selecting suppliers and allocating orders. Mafakheri et al. (2011) [12] and other scholars proposed a two-stage method. These scholars applied AHP to rank potential suppliers in the first stage, and goal programming was used to solve maximum TVP (Total Cost of Procurement) and minimum TCP (Total Cost of Procurement) in the second stage. Shaw et al. (2012) [13] chose Fuzzy AHP and fuzzy objectives to select suppliers. In this model, Fuzzy AHP was used to calculate weighted values, and these values were applied to goal programming model for supplier selection. Qian (2014) [4] analyzed many important factors in supplier selection in detail, including purchasing cost, delivery performance, profit, and lean production. And these factors were taken into account in different markets with certain demands and uncertain demands to balance the profit and supplier selection. Choudhary and Shankar (2014) [14] set a model about inventory, supplier selection, and transportation programming problem solved by the goal programming model, and solutions were compared to analyze advantages and disadvantages of different methods. Kar (2015) [15] combined Neural Network Algorithm, AHP, and fuzzy sets to select suppliers. And Scott et al. (2015) [16] with other scholars combined AHP and QFD to make the research about requirements from stakeholders in supplier selection.

From the above literatures, single objective programming is used the most for supplier selection. But multiobjective programming is used in this paper because we consider more about the relevance among different objectives. Meanwhile, the corresponding order allocation can be obtained after solving supplier selection problem. What is more, Fuzzy AHP is used instead of AHP to calculate weighted values, because this method is more reasonable for supplier selection and order allocation in real life situation.

\section{Model Formulation}

In this paper, we assume that long period marketing regulation makes the demands from customers predictable. And single product is considered for supplier selection and order allocation in this paper. In this problem, a manufacturer has $n$ alternative suppliers and makes plans over $t$ periods. When considering customer demands, a manufacturer must consider order fulfillment, especially in the Build-to-Order supply chain according to Ye et al. (2006) [17] and other scholars, because it reflects the service level and the cost of inventory. And the higher the service level is, the more the cost of inventory will be. What is more, the delivery performance and goods quality of a supplier have an effect on purchasing quantity. And it should be mentioned that rejected items rate and late delivery items rate are also the factors for supplier selection and order allocation.

Other assumptions are shown as follows:

(i) demands of product over each period can be predicted;

(ii) both stock shortage and overstocked products are allowed;

(iii) the productivity of a supplier is limited;

(iv) cooperative cost only occurs when products are purchased from a supplier;

(v) holding cost of inventory only occurs when products are held over more than one period;

(vi) late delivery items will be received at the next period;

(vii) rejected items will be disposed, and they will not be regarded as inventory when held over more than one period;

(viii) late delivery items will be regarded as qualified items, and suppliers have enough time to check them before sending; 
(ix) a minimum order quantity is required.

Based on the assumptions mentioned above, index, parameters, and decision variables are considered as shown in Notations.
To select optimum suppliers, we set three objective functions to minimize net rejected items as $Z_{1}$, late delivery items as $Z_{2}$, and purchasing cost as $Z_{3}$. So, this problem can be formulated as

$$
\begin{array}{ll}
\text { Minimize } \quad Z_{1} & =\sum_{i=1}^{n} \sum_{t=1}^{T} x_{i t} R_{i t} \\
\text { Minimize } \quad Z_{2} & =\sum_{i=1}^{n} \sum_{t=1}^{T} x_{i t} L_{i t} \\
\text { Minimize } \quad Z_{3} & =\sum_{i=1}^{n} \sum_{t=1}^{T} x_{i t} P_{i t}+\sum_{i=1}^{n} \sum_{t=1}^{T} O_{i t} y_{i t}+\sum_{i=1}^{n} h_{t} C_{t} \\
\text { Subject to } \quad C_{t-1}+\sum_{i=1}^{n} x_{i t}-\sum_{i=1}^{n} x_{i t} L_{i t}+\sum_{i=1}^{n} x_{i(t-1)} L_{i(t-1)}-\sum_{i=1}^{n} x_{i t} R_{i t}-d_{t}-S_{t-1}=C_{t}-S_{t}, \quad \forall t \\
x_{i t} \leq\left(\sum_{k=t}^{T} d_{k}\right) y_{i t}, \quad \forall t, \quad \forall i \\
x_{i t} \leq U_{i t}, \quad \forall t, \quad \forall i \\
C_{t} \leq \omega, \quad \forall t \\
S_{t} \leq\left(1-\theta_{t}\right) d_{t}, \quad \forall t \\
x_{i t}+\left(1-y_{i t}\right) \cdot M \geq B_{i t}, \quad \forall t, \forall i \\
S_{t} \geq 0, \quad \forall t \\
C_{t} \geq 0, \quad \forall t \\
x_{i t} \geq 0 \text { and integer, } \forall t, \quad \forall i \\
y_{i t} \in\{0,1\}, \quad \forall t, \quad \forall i .
\end{array}
$$

We assume that (1), (2), and (3) are all subject to above constraints, including the balance of goods flow, purchasing quantity, supply ability, stock shortage, and minimum order quantity. Equation (4) is the balance of goods flow. Equation (5) means the reasonable order allocation, because, at each period, orders should not exceed total demand. Equation (6) shows that order allocation to a supplier cannot exceed its productivity. Equation (7) is the maximum inventory level and (8) means that, at the service level $\theta$, the rate $(1-\theta)$ can be used to reflect stock shortage. Equation (9) is the minimum order quantity set by suppliers. Equations (10) to (13) are nonnegative constraints and integral sets.

It is noticeable that rejected items and late delivery items from manufacturers are taken into account. In real life situation, rejected items and late delivery items have the impact on inventory, which means that they affect order allocation. Figure 1 shows that, over $t$ period, the inventory cost and stock shortage of a manufacturer are affected by the inventory and stock shortage over $(t-1)$ period. And the late delivery items from $(t-1)$ period are added to $t$ period.

\section{Methods to Solve Supplier Selection and Order Allocation}

Generally, a single Crisp Formulation [8] is used to solve supplier selection and order allocation. But this method fails to consider the weighted value of each objective function. So, a weighted-additive model is proposed by Tiwari et al. [18]. It can be presented by

$$
\begin{aligned}
\mu_{D}(x) & =\sum_{j=1}^{J} w_{j} \mu_{z j}(x)+\sum_{k=1}^{K} \beta_{k} \mu_{g k}(x) \\
\sum_{j=1}^{J} w_{j}+\sum_{k=1}^{K} \beta_{k} & =1, \quad w_{j} \geq 0, \quad \beta_{k} \geq 0,
\end{aligned}
$$




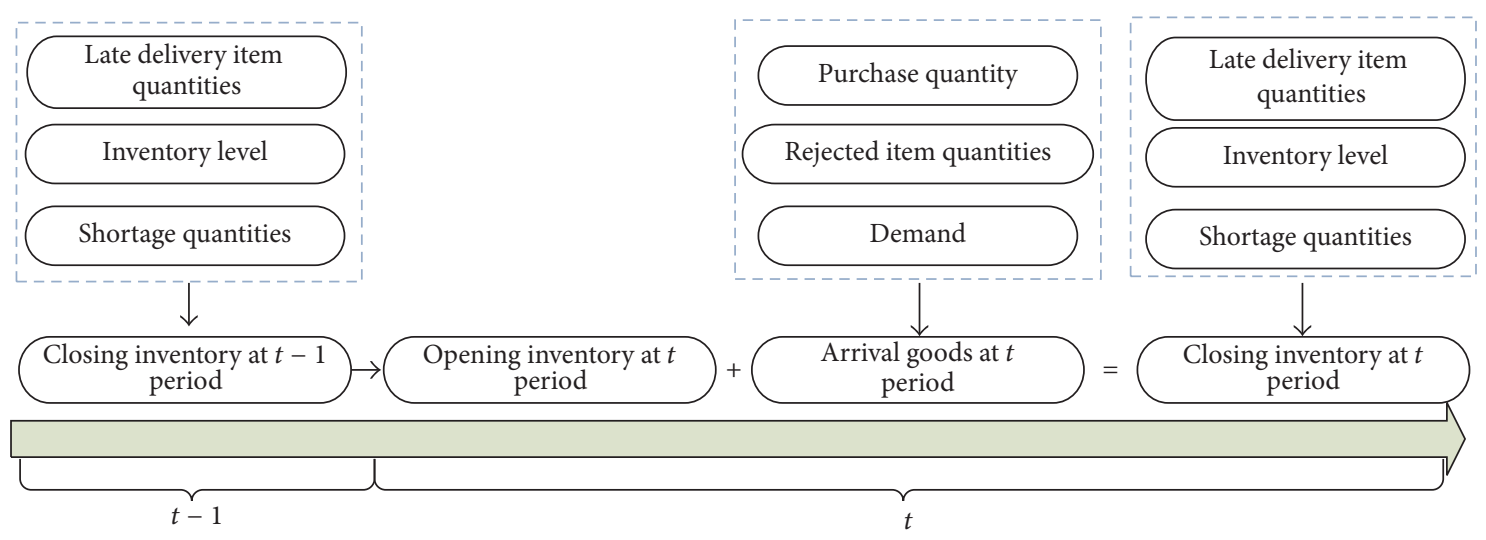

FIGURE 1: Balance of goods flow.

TABLE 1: The importance of AHP [10].

\begin{tabular}{lc}
\hline Number & Importance \\
\hline 1 & Same importance \\
3 & Slight importance \\
5 & General importance \\
7 & Strong importance \\
9 & Extreme importance \\
$2,4,6,8$ & Balanced value \\
\hline
\end{tabular}

where $w_{j}$ and $\beta_{k}$ are the weighted values of each objective function. $\mu_{z j}(x)$ and $\mu_{g k}(x)$ are the membership degree proposed by Zadeh [3], which can be presented by

$$
\begin{aligned}
& \mu_{Z j}(x) \\
& = \begin{cases}1, & \text { if } z_{j}(x) \leq z_{j}^{\min } \\
\frac{\left[z_{j}^{\max }-z_{j}(x)\right]}{\left[z_{j}^{\max }-z_{j}^{\min }\right]}, & \text { if } z_{j}^{\min } \leq z_{j}(x) \leq z_{j}^{\max } j=1,2, \ldots, J \\
0, & \text { if } z_{j}(x) \geq z_{j}^{\max },\end{cases}
\end{aligned}
$$

where $Z_{j}^{\max }$ is the upper bound that can be found by maximizing feasible solutions of the objective function. In the same way, $Z_{j}^{\mathrm{min}}$ is the lower bound that can be found by minimizing feasible solutions of the objective functions. The membership degree in this paper is used to calculate the proportion of each criterion, so it is critical to final result with weighted values.

However, weighted values in the weighted-additive model are often decided by decision makers subjectively or calculated by conventional AHP, which is not accurate enough. So, in order to make the result more reasonable in real life situation, we use FAHP to calculate the weighted values. Experts score each target according to the importance shown in Table 1, and a corresponding comparison matrix will be made. After that, the comparison matrix is transformed into triangular fuzzy numbers according to the principle proposed by Lee (2009) [10], shown in Table 2 . Then the weighted value of each objective function can be calculated.
TABLE 2: Transformed fuzzy number [10].

\begin{tabular}{lc}
\hline Fuzzy number & Characteristic function \\
$\widehat{\widehat{1}}$ & $(1,1,2)$ \\
$\widehat{x}$ & $(x-1, x, x+1), x=2,3,4,5,6,7,8$ \\
$\widehat{9}$ & $(8,9,9)$ \\
$1 / \widehat{1}$ & $\left(2^{-1}, 1^{-1}, 1^{-1}\right)$ \\
$1 / \widehat{x}$ & $\left((x+1)^{-1}, x^{-1},(x-1)^{-1}\right), x=2,3,4,5,6,7,8$ \\
$1 / \widehat{9}$ & $\left(9^{-1}, 9^{-1}, 8^{-1}\right)$ \\
\hline
\end{tabular}

According to the weighted-additive model, we propose the model

$$
\max =w_{z j} \cdot r_{z j}
$$

Subject to (4) to (13),

where $w_{z j}$ is the weighted value solved by FAHP and $r_{z j}$ is the membership degree of each objective function. This model involves weighted values solved by FAHP to make the result more reasonable, and it can simplify the calculation compared to weighted-additive model. So, it is used to solve supplier selection and order allocation problem in this paper.

To conclude, the above illustrations demonstrate the necessary improvement of the single Crisp Formulation when solving a multiobjective programming problem without weighted values. And a weighted model with membership degree and weighted values based on FAHP approach is more reasonable to solve supplier selection and order allocation in real life situations.

Six steps will be involved in solving this problem, and these steps are considered as follows.

Step 1. Decide which criterion should be scored by experts. Generally, AHP is widely used to rank the importance of many factors. But FAHP is used to calculate the weighted values in this paper.

Step 2. Experts will score those criteria from 1 to 9 according to the importance shown in Table 1. And several comparison matrices are made. 
TABLE 3: Rejected items rate.

\begin{tabular}{ccccccccccccc}
\hline & Jan. & Feb. & Mar. & Apr. & May & Jun. & Jul. & Aug. & Sept. & Oct. & Nov. & Dec. \\
\hline$S_{1}$ & 0.02 & 0.02 & 0.02 & 0.05 & 0.05 & 0.02 & 0.02 & 0.05 & 0.05 & 0.05 & 0.05 & 0.05 \\
$S_{2}$ & 0.02 & 0.02 & 0.02 & 0.02 & 0.02 & 0.1 & 0.02 & 0.02 & 0.02 & 0.05 & 0.02 & 0.02 \\
$S_{3}$ & 0.05 & 0.05 & 0.05 & 0.02 & 0.1 & 0.05 & 0.1 & 0.02 & 0.02 & 0.1 & 0.1 & 0.05 \\
\hline
\end{tabular}

TABLE 4: Late delivery items rate.

\begin{tabular}{|c|c|c|c|c|c|c|c|c|c|c|c|c|}
\hline & Jan. & Feb. & Mar. & Apr. & May & Jun. & Jul. & Aug. & Sept. & Oct. & Nov. & Dec. \\
\hline$S_{1}$ & 0.01 & 0.01 & 0.01 & 0.01 & 0.01 & 0.01 & 0.01 & 0.01 & 0.01 & 0.01 & 0.01 & 0.01 \\
\hline$S_{2}$ & 0.01 & 0.01 & 0.01 & 0.05 & 0.05 & 0.01 & 0.01 & 0.01 & 0.01 & 0.01 & 0.01 & 0.01 \\
\hline$S_{3}$ & 0.05 & 0.05 & 0.05 & 0.05 & 0.05 & 0.05 & 0.05 & 0.05 & 0.05 & 0.05 & 0.05 & 0.05 \\
\hline
\end{tabular}

TABLE 5: Demand.

\begin{tabular}{cccccccccccc}
\hline Jan. & Feb. & Mar. & Apr. & May & Jun. & Jul. & Aug. & Sept. & Oct. & Nov. & Dec. \\
\hline 100 & 80 & 100 & 60 & 80 & 120 & 80 & 70 & 80 & 100 & 60 & 100 \\
\hline
\end{tabular}

TABLE 6: Purchasing cost per unit.

\begin{tabular}{ccccccccccccc}
\hline & Jan. & Feb. & Mar. & Apr. & May & Jun. & Jul. & Aug. & Sept. & Oct. & Nov. & Dec. \\
\hline$S_{1}$ & 2.4 & 2.45 & 2.46 & 2.25 & 2.29 & 2.31 & 2.39 & 2.41 & 2.38 & 2.35 & 2.36 & 2.2 \\
$S_{2}$ & 2.46 & 2.42 & 2.45 & 2.26 & 2.3 & 2.3 & 2.35 & 2.42 & 2.4 & 2.3 & 2.26 & 2.18 \\
$S_{3}$ & 2.42 & 2.46 & 2.46 & 2.255 & 2.3 & 2.32 & 2.28 & 2.4 & 2.41 & 2.32 & 2.23 & 2.2 \\
\hline
\end{tabular}

TABLE 7: Others.

\begin{tabular}{lccc}
\hline & Supply ability (tons) & Cooperative cost (10 thousand RMB) & Minimum order quantity (tons) \\
\hline$S_{1}$ & 250 & 3 & 10 \\
$S_{2}$ & 70 & 1.2 & 10 \\
$S_{3}$ & 80 & 1.5 & 10 \\
\hline
\end{tabular}

Step 3. After that, these comparison matrices are transformed to fuzzy numbers according to Table 2 .

Step 4. Use FAHP to calculate weighted values.

Step 5. Under constraints (4) to (13), three objective functions are solved. By maximization, upper bound $Z_{j}^{\max }$ can be obtained, and by minimization, lower bound $Z_{j}^{\min }$ can be obtained.

Step 6. Weighted values solved in Step 4 and the membership degree of each objective function are added to the weighted model (15). Finally, the result of supplier selection and order allocation can be calculated.

\section{A Case Study}

5.1. Data Description. Data from a plastic and textile company (hereinafter to be referred to as KF Company) are used to check the feasibility of the weighted model. Maximum inventory for KF Company to store nylon is 40 tons, and the inventory cost is 1 thousand $\mathrm{RMB}$ per unit ton. The nylon comes from three suppliers, $S_{1}, S_{2}$, and $S_{3}$, respectively, and related data in 2014 are shown in Tables 3-7.

5.2. Calculating by FAHP. According to three objective functions mentioned in Section 3, a questionnaire is designed, and experts in KF Company score the importance of three criteria. Then six questionnaires are received and we transform them into six comparison matrices shown in Table 8. And Matlab is used to check their consistency. If a matrix cannot qualify the consistency, it may be the incorrect scores from experts. So, experts need to check it again until all matrices qualify the consistency after programming.

According to Table 8, six comparison matrices are transformed into a fuzzy matrix. And the final scoring result is shown in Table 9.

The weighted values are shown in Table 10.

From the result analyzed in Table 10, quality weighs the most for supplier selection, the following weight is purchasing cost, and delivery performance is the least. A manager from KF Company said that, in order to achieve more satisfaction from customers for longer cooperation, they put more emphasis on quality. He also said that the reason why 
TABLE 8: Comparison matrices.

\begin{tabular}{|c|c|c|c|}
\hline & Cost & Quality & Delivery performance \\
\hline \multicolumn{4}{|l|}{ Comparison matrix 1} \\
\hline Cost & 1 & 1 & 3 \\
\hline Quality & 1 & 1 & 3 \\
\hline Delivery performance & $1 / 3$ & $1 / 3$ & 1 \\
\hline \multicolumn{4}{|l|}{ Comparison matrix 2} \\
\hline Cost & 1 & $1 / 2$ & 3 \\
\hline Quality & 2 & 1 & 5 \\
\hline Delivery performance & $1 / 3$ & $1 / 5$ & 1 \\
\hline \multicolumn{4}{|l|}{ Comparison matrix 3} \\
\hline Cost & 1 & $1 / 3$ & 4 \\
\hline Quality & 3 & 1 & 6 \\
\hline Delivery performance & $1 / 4$ & $1 / 6$ & 1 \\
\hline \multicolumn{4}{|l|}{ Comparison matrix 4} \\
\hline Cost & 1 & 1 & 2 \\
\hline Quality & 1 & 1 & 3 \\
\hline Delivery performance & $1 / 2$ & $1 / 3$ & 1 \\
\hline \multicolumn{4}{|l|}{ Comparison matrix 5} \\
\hline Cost & 1 & $1 / 2$ & 3 \\
\hline Quality & 2 & 1 & 4 \\
\hline Delivery performance & $1 / 3$ & $1 / 4$ & 1 \\
\hline \multicolumn{4}{|l|}{ Comparison matrix 6} \\
\hline Cost & 1 & 1 & 3 \\
\hline Quality & 1 & 1 & 4 \\
\hline Delivery performance & $1 / 3$ & $1 / 4$ & 1 \\
\hline
\end{tabular}

delivery performance weighed the least was because they had stable customers, and orders were given in advance so that manufacturing could be organized well. However, if KF Company wants to expand market to receive more orders from the retailer, delivery performance and other factors are needed to be considered more.

5.3. Computational Results. At the service level of 0.99, 0.90, and 0.8 , we program the objective function with weighted values and maximum membership degree. The programming is implemented with Lingo 11.0 in less than 5 minutes. And the computer's type is Intel ${ }^{\circledR}$ Celeron U3400 and CPU is $1.1 \mathrm{GHZ}$. Table 11 shows the minimum and maximum values of the function at different service levels.

The result of service level at 0.99 is taken as an example, plotting its graph for membership function of quality, delivery performance, and purchasing cost, shown in Figure 2.

The results of weighted model are shown in Tables 1214. Three suppliers are all selected over the planning period during twelve months. The value of cost function is an upward trend with the rise of service level while the value of quality function and delivery performance function is stable.

The single Crisp Formulation without weighted values is also solved under the same sets, and the results are shown in Table 15.

\section{Result Analysis}

By using the weighted model and single Crisp Formulation solving this problem, we illustrate the results by charts and diagrams. Taking an example, at the service level 0.99 , we can show the purchasing quantities in Figure 3 and the actual shortage of goods in Figure 4. Although the scale of this problem is relatively small, two charts still reflect an obvious difference of purchasing quantities, and this difference occurs in April, May, August, and October, which means that the weighed values indeed affect order allocation.

Besides the illustration mentioned above, another method is used to demonstrate the difference between two results. In view of the different metrics of different functions, Value Path Approach (VPA) [13] can be used to set a norm for these compared results. That is to say, each objective functional value can be standardized by dividing a minimum functional value at the same service level. After being standardized, all functions are dimensionless; as a result, the smaller the VPA value of a minimized function is, the more reasonable the result is. Table 16 illustrates the functional values with corresponding VPA values at different service levels given by two methods.

Figure 4 shows the standardized results of functional values. When the service level is 0.99 , by means of VPA, we can demonstrate that the single Crisp Formulation is more advantageous than the weighted model in purchasing cost and delivery performance, at $10.31 \%$ and $0.13 \%$, respectively, and $2 \%$ less in quality. When the service level is 0.9 , delivery performance of the single Crisp Formulation is $10.74 \%$ more than the weighed model, but quality is $4.1 \%$ less and purchasing cost is $0.01 \%$ less. When the service level is 0.8 , delivery performance solved by the single Crisp Formulation is $11.19 \%$ more than the weighted model while quality and purchasing cost are less, $5.46 \%$ and $0.93 \%$, respectively. In summary, delivery performance is more advantageous in the single Crisp Formulation, which means that net late delivery items are less and suppliers are better in delivery performance. And the fluctuation of purchasing cost between two methods is not obvious, and the result of quality in the single Crisp Formulation is inferior to the weighted model. This means that net rejected items in the single Crisp Formulation are more than the weighted model.

What is more, Figure 5 also demonstrates that standardized VPA value of quality and delivery performance is shattered, which indicates that the weighted values added to quality and delivery performance have an impact on their functions. As for purchasing cost, the VPA value is similar in two methods. So, we conclude that the cost function is not sensitive to its weighted value. Besides, the importance of three functions is the same in the single Crisp Formulation. That is to say, two weighted values of purchasing cost are similar. So, two results of purchasing cost are similar between two methods. However, weighted values of quality and delivery performance solved by FAHP show a large discrepancy between two methods. So, net rejected items are decreased but late delivery items are increased in the weighted model. All in all, the weighted model makes the purchase strategy prefer the function of high weighed values such as cost 

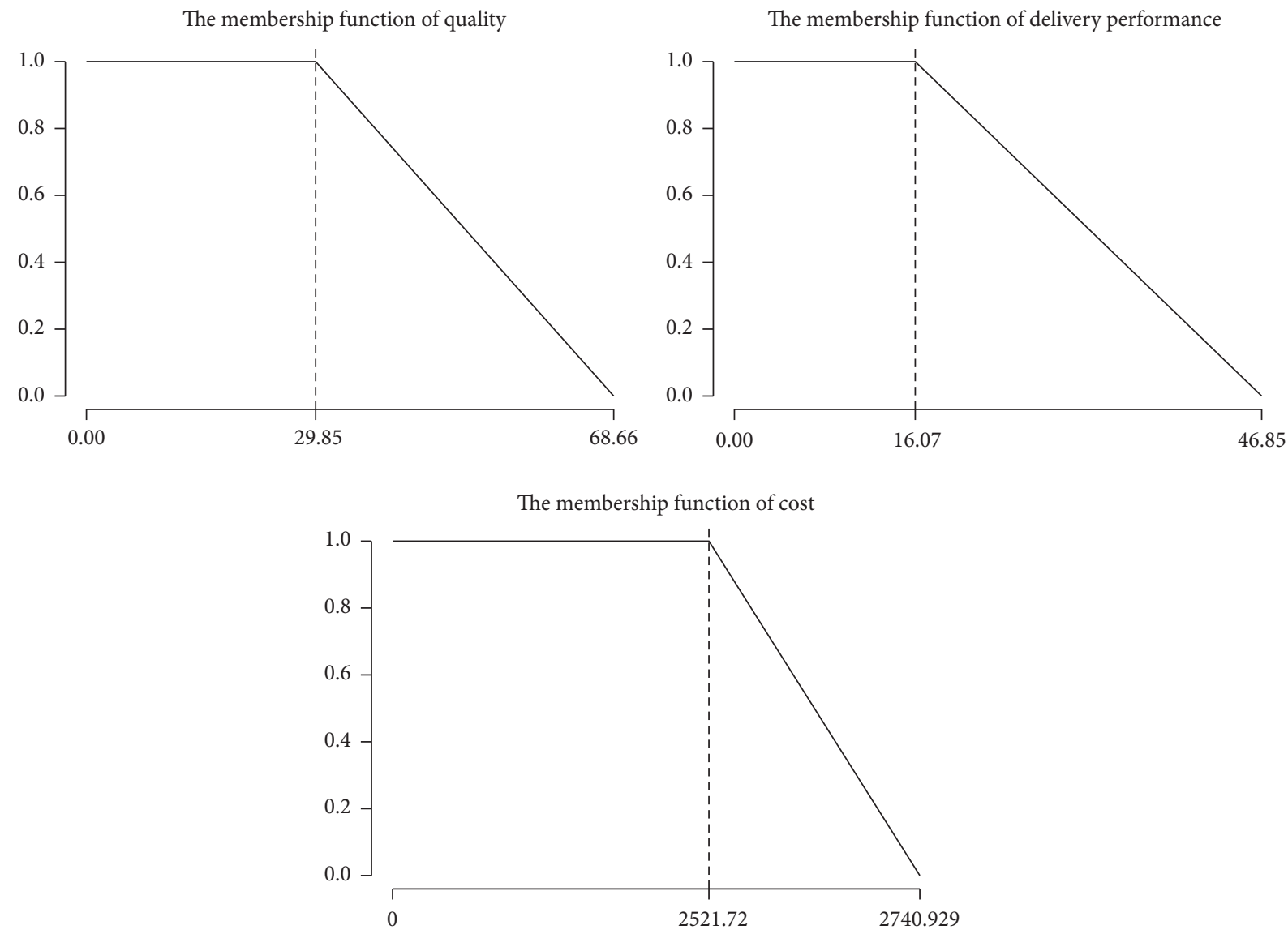

Figure 2: Membership functions.
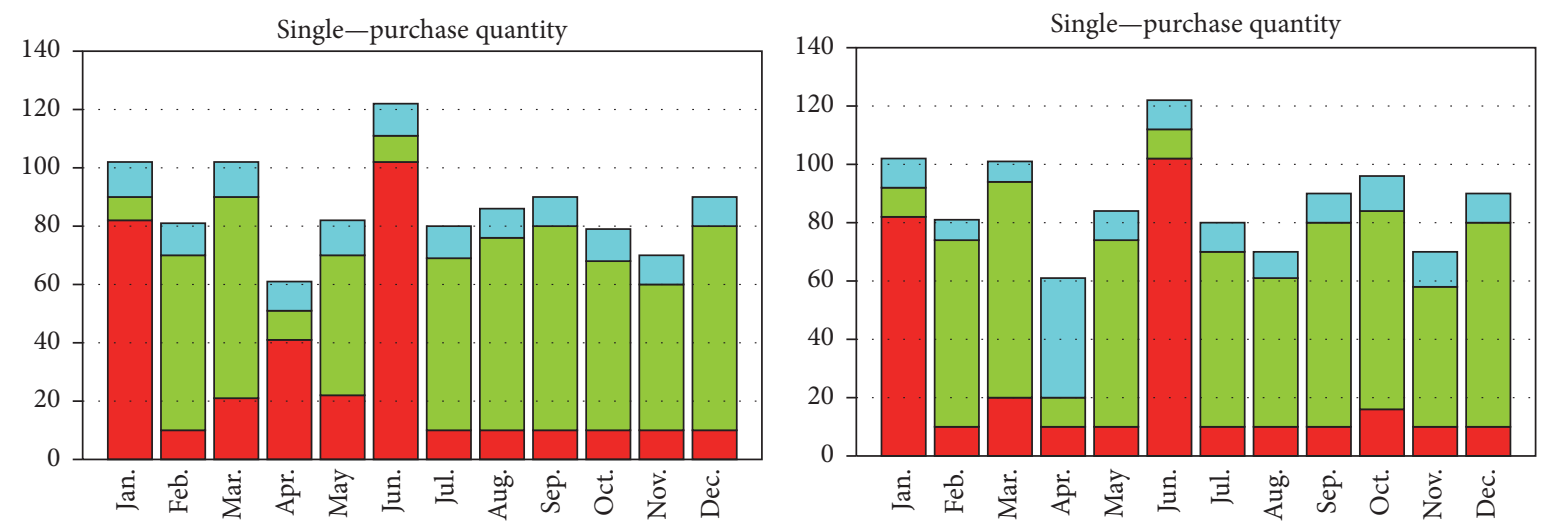

- Supplier 1

- Supplier 2

- Supplier 3

- Supplier 1

- Supplier 2

- Supplier 3

Figure 3: Comparison of purchasing quantity.

TABLE 9: Fuzzy comparison matrix.

\begin{tabular}{lccc}
\hline & Purchasing cost & Quality & Delivery performance \\
\hline Cost & $(1,1,2)$ & $(0.55,0.661,1.26)$ & $(1.906,2.942,3.957)$ \\
Quality & $(1.122,1.513,2.57)$ & $(1,1,2)$ & $(2.994,4.036,5.061)$ \\
Delivery performance & $(0.253,0.34,0.525)$ & $(0.198,0.248,0.334)$ & $(1,1,1.782)$ \\
\hline
\end{tabular}


TABLE 10: Weighted values.

\begin{tabular}{lccc}
\hline & Purchasing cost & Quality & Delivery performance \\
\hline Weighted value & 0.38 & 0.52 & 0.1 \\
\hline
\end{tabular}

TABLE 11: Critical values.

\begin{tabular}{|c|c|c|c|c|c|c|}
\hline \multirow{2}{*}{$\begin{array}{l}\text { Service level } \\
\text { Objective function }\end{array}$} & \multicolumn{2}{|c|}{$\theta=0.99$} & \multicolumn{2}{|c|}{$\theta=0.90$} & \multicolumn{2}{|c|}{$\theta=0.80$} \\
\hline & $\mu=0$ & $\mu=1$ & $\mu=0$ & $\mu=1$ & $\mu=0$ & $\mu=1$ \\
\hline Quality & 68.66 & 29.85 & 68.95 & 29.38 & 68.95 & 28.85 \\
\hline Delivery performance & 46.85 & 16.07 & 47.18 & 15.98 & 47.18 & 15.88 \\
\hline Purchasing cost & 2740.93 & 2512.72 & 2743.61 & 2497.59 & 2743.75 & 2471.25 \\
\hline
\end{tabular}

TABLE 12: Purchasing quantity.

\begin{tabular}{ccccccccccccccc}
\hline & & Jan. & Feb. & Mar. & Apr. & May & Jun. & Jul. & Aug. & Sept. & Oct. & Nov. & Dec. \\
\hline \multirow{3}{*}{$\theta=0.99$} & $S_{1}$ & 83 & 10 & 21 & 10 & 10 & 103 & 10 & 10 & 10 & 15 & 10 & 10 \\
& $S_{2}$ & 10 & 62 & 70 & 10 & 65 & 10 & 60 & 51 & 70 & 70 & 49 & 70 \\
& $S_{3}$ & 10 & 10 & 10 & 42 & 10 & 10 & 10 & 10 & 10 & 10 & 10 & 10 \\
\hline \multirow{3}{*}{$\theta=0.90$} & $S_{1}$ & 83 & 10 & 12 & 10 & 10 & 111 & 10 & 10 & 10 & 10 & 10 & 11 \\
& $S_{2}$ & 10 & 62 & 70 & 10 & 57 & 10 & 60 & 51 & 70 & 65 & 49 & 70 \\
& $S_{3}$ & 10 & 10 & 10 & 52 & 10 & 10 & 10 & 10 & 10 & 10 & 10 & 10 \\
\hline \multirow{3}{*}{$\theta=0.80$} & $S_{1}$ & 83 & 10 & 10 & 10 & 10 & 119 & 11 & 10 & 10 & 10 & 10 & 10 \\
& $S_{2}$ & 10 & 61 & 64 & 11 & 48 & 10 & 59 & 60 & 70 & 45 & 51 & 70 \\
& $S_{3}$ & 10 & 10 & 10 & 60 & 10 & 10 & 10 & 10 & 10 & 10 & 10 & 10 \\
\hline
\end{tabular}

TABLE 13: Membership degree.

\begin{tabular}{lcccr}
\hline & Maximum & Quality & Delivery performance & Purchasing cost \\
\hline$\theta=0.99$ & 0.956162 & 0.973718 & 0.88564 & 0.950695 \\
$\theta=0.90$ & 0.953133 & 0.973212 & 0.884295 & 0.943772 \\
$\theta=0.80$ & 0.957217 & 0.981546 & 0.884984 & 0.942932 \\
\hline
\end{tabular}

TABLE 14: Function values.

\begin{tabular}{lccc}
\hline & $\theta=0.99$ & $\theta=0.90$ & $\theta=0.80$ \\
\hline$Z_{1}$ & 30.87 & 30.44 & 29.59 \\
$Z_{2}$ & 19.59 & 19.59 & 19.48 \\
$Z_{3}$ & 2530.45 & 2509.89 & 2484.07 \\
\hline
\end{tabular}

TABLE 15: Results of single Crisp Formulation.

\begin{tabular}{lccc}
\hline & $\theta=0.99$ & $\theta=0.90$ & $\theta=0.80$ \\
\hline Quality & 31.79 & 31.74 & 31.30 \\
Delivery performance & 17.57 & 17.69 & 17.52 \\
Purchasing cost & 2527.03 & 2510.29 & 2507.37 \\
Maximum membership degree & 0.950013 & 0.932582 & 0.950641 \\
\hline
\end{tabular}

TABLE 16: Comparison of quality, delivery performance, and cost functions.

\begin{tabular}{lcccccc}
\hline Service level & \multicolumn{2}{c}{$\theta=0.99$} & \multicolumn{2}{c}{$\theta=0.90$} & \multicolumn{2}{c}{$\theta=0.80$} \\
& Single & Weighted & Single & Weighted & Single & Weighted \\
\hline Quality & 31.79 & 30.87 & 31.74 & 30.44 & $(1.30$ & $(1.0578)$ \\
VPA quality & $(1.0298)$ & $(1.0000)$ & $(1.0427)$ & $(1.0000)$ & 1.59 \\
Delivery performance & 17.57 & 19.59 & 17.69 & 19.59 & $(1.0000)$ \\
VPA delivery & $(1.0000)$ & $(1.1150)$ & $(1.0000)$ & $(1.1074)$ & $(1.0000)$ & $(1.1119)$ \\
Cost & 2527.03 & 2530.45 & 2510.29 & 2509.89 & 2507.37 & 2484.07 \\
VPA cost & $(1.0000)$ & $(1.0014)$ & $(1.0002)$ & $(1.0000)$ & $(1.0094)$ & $(1.0000)$ \\
\hline
\end{tabular}




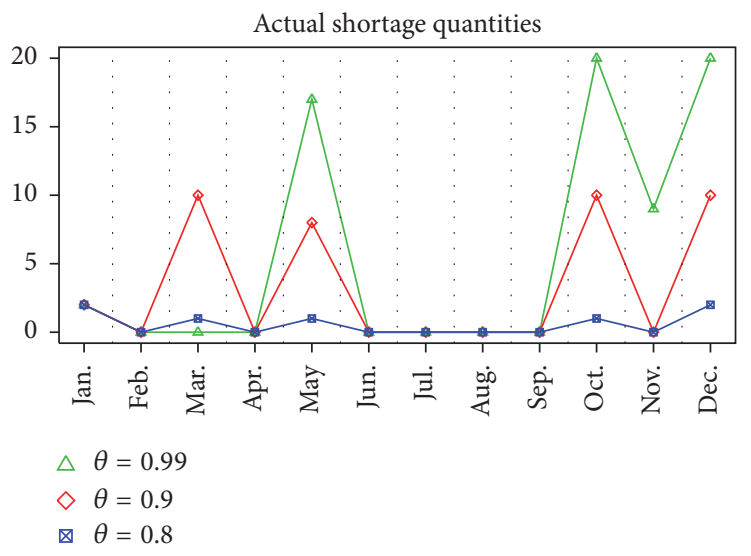

Figure 4: Actual shortage with different service level.

function, showing the asymmetry of this problem. At the same time, service level affects net rejected items and late delivery items more than purchasing cost.

Figure 6 illustrates different service levels and solving methods will have the impact on the results. For all service levels, weighted results of quality and purchasing cost are close to 1 , and delivery performance is above 1 ; while results of quality solved by Crisp Formulation is above 1, delivery performance and purchasing cost are close to 1. For quality, the VPA value of Crisp Formulation is larger than the weighted model, and the higher the service level is, the smaller the VPA value is. For delivery performance, the VPA value is larger in weighted model with a more centralized distribution so that it has a larger difference than the result of Crisp Formulation. This reflects the same conclusion shown in Figure 5, indicating that service level has a direct impact on net rejected items and net late delivery items. As for purchasing cost, although the VPA value of Crisp Formulation is more than 1, it is almost the same as the result of weighted model. This figure can further illustrate quality and delivery performance are more sensitive to the weighted value solved by FAHP, and it can affect net rejected items and late delivery items, but purchasing cost is insensitive to the weighted value and slightly affects net rejected items and late delivery items.

Figure 7 tells us that, at the service level of 0.99 , stock shortage fluctuates obviously for the single Crisp Formulation, but, for the weight model, it is stable. This indicates that weighted values have a positive effect on inventory.

The membership degree for Crisp Formulation and the weighted model are shown in Table 17.

Finally, the trend of maximum membership value at different service levels with different solving methods is shown in Figure 8. It is obvious that all membership values of the single Crisp Formulation are smaller than the weighted model, which means that weighted model can obtain a higher membership degree with high weighted values. So an optimum solution can be obtained, and it is more reasonable in real life situation.

\section{Conclusions}

There is no doubt that supplier selection is a complex task because it is hard to keep the balance among all criteria.
Therefore, if a manufacturer wants to obtain a sustainable market, supplier selection and order allocation play the crucial role in a supply chain.

This paper uses FAHP to calculate weighted values, and two results from single Crisp Formulation and the weighted model are compared to further illustrate some advantages of FAHP solving weighted values. Nevertheless, some related issues should be proposed for future researches.

(1) Large-Scale Problems. With the increasing of planning periods and the number of suppliers, the calculation of the model will be more difficult, because Lingo is generally applied in small-scale problems. So, heuristic algorithm should be used such as genetic algorithm to solve this problem.

(2) Demand Uncertainty. Certain demand of the market is assumed in this paper. But if some industries such as clothing with great fluctuation need to select suppliers, the model needs to be improved with random demands.

(3) Diversity of Products. Supplier selection and order allocation are harder to be solved when products are various. In fact, many companies produce more than one sort of product. So, in future researches, a hybrid approach proposed by Yang and Dong (2012) [19] is used to solve product configuration problems for supplier selection and order allocation.

\section{Notations}

Index Set

$i$ : Index for supplier, for all $i=1,2, \ldots, I$

$j$ : Index for objective function, for $j=1,2, \ldots, J$

$t$ : Index for period, $t=1,2, \ldots, T$

\section{Parameters}

$\omega$ : Maximum inventory

$w_{e j}$ : Weighted value of objective function $j$ 

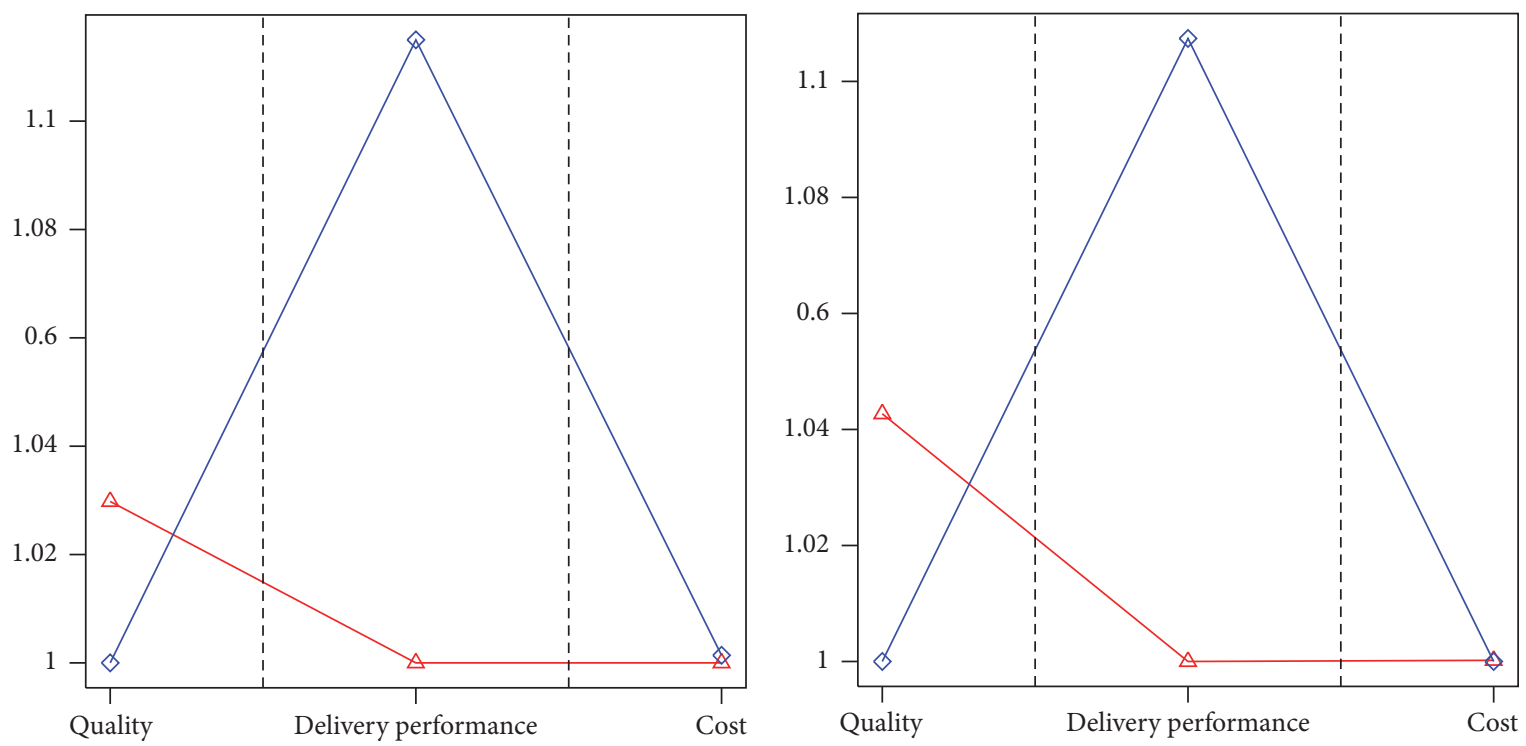

$\triangle$ Single
$\diamond$ Weighted

$\triangle$ Single

$\diamond$ Weighted

$\theta=0.99$

$\theta=0.9$

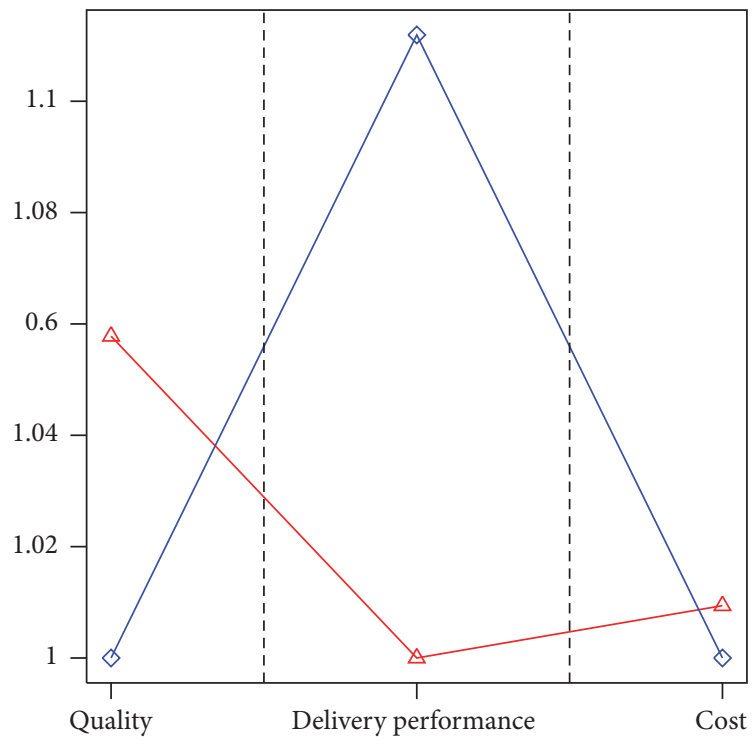

$\triangle$ Single

$\diamond$ Weighted

$$
\theta=0.8
$$

FIGURE 5: Comparison of single Crisp Formulation and weighted model.

TABLE 17: Comparison of maximum membership degree.

\begin{tabular}{lcccccr}
\hline \multirow{2}{*}{ Service level } & \multicolumn{2}{c}{$\theta=0.99$} & \multicolumn{2}{c}{$\theta=0.90$} & \multicolumn{2}{c}{$\theta=0.80$} \\
& Single & Weighted & Single & Weighted & Single & Weighted \\
\hline Maximum & 0.950013 & 0.956162 & 0.932582 & 0.953133 & 0.950641 & 0.957216 \\
\hline
\end{tabular}



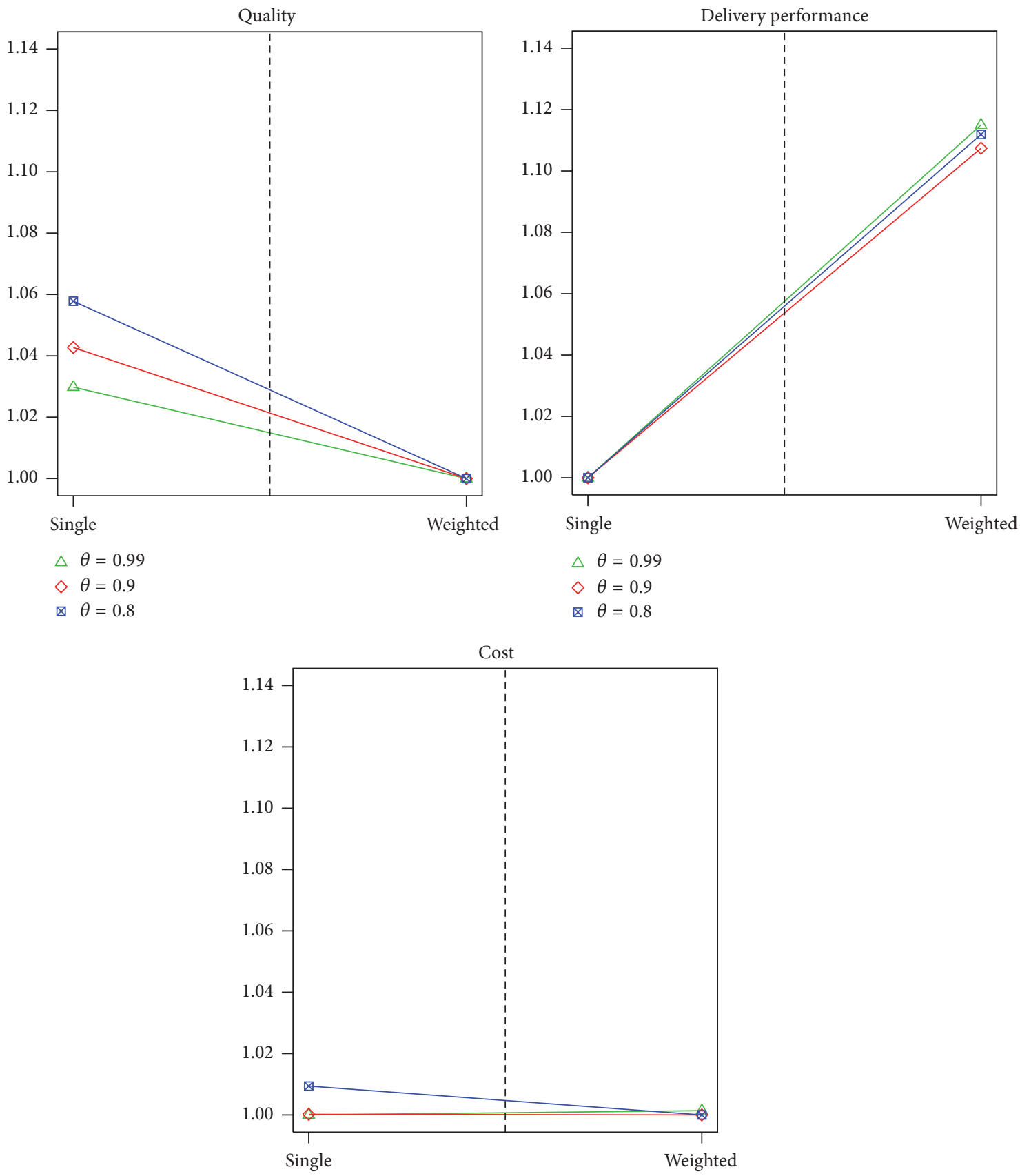
$\triangle \theta=0.99$
$\diamond \theta=0.9$
$\otimes \theta=0.8$

FIGURE 6: Comparison among different service levels.

$r_{e j}:$ Membership of objective function $j$

$z_{j}^{+}$: Upper bound of objective function $j$

$z_{j}^{-}$: Lower bound of objective function $j$

$P_{i t}$ : Purchasing cost from supplier $i$ over $t$ period

$R_{i t}$ : Rejected items rate from supplier $i$ over $t$ period

$B_{i t}$ : Minimum order quantity of supplier $i$ over $t$ period
$L_{i t}$ : Late delivery items rate from supplier $i$ over $t$ period

$U_{i t}$ : Maximum supply ability of supplier $i$ over $t$ period

$\mathrm{O}_{i t}$ : Cooperative cost between manufacturer and supplier $i$ over $t$ period

$d_{t}$ : Marketing demand over $t$ period

$h_{t}$ : Inventory holding cost of manufacturer over $t$ period 


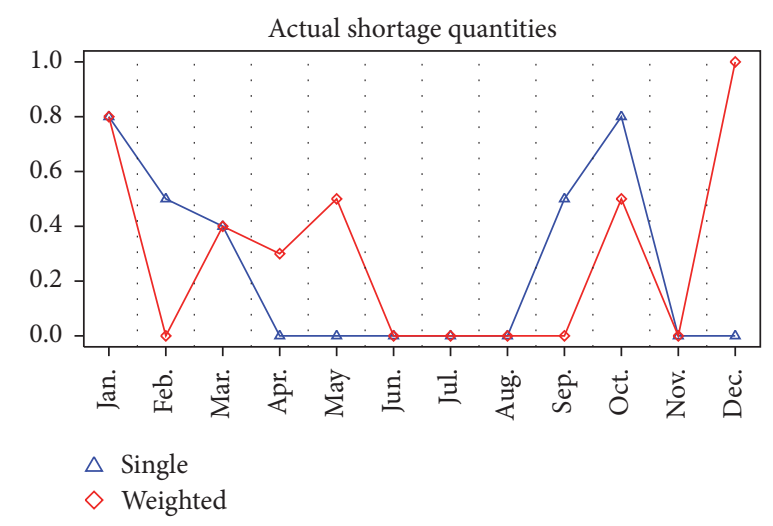

Figure 7: Actual shortage quantities at the service level of 0.99 .

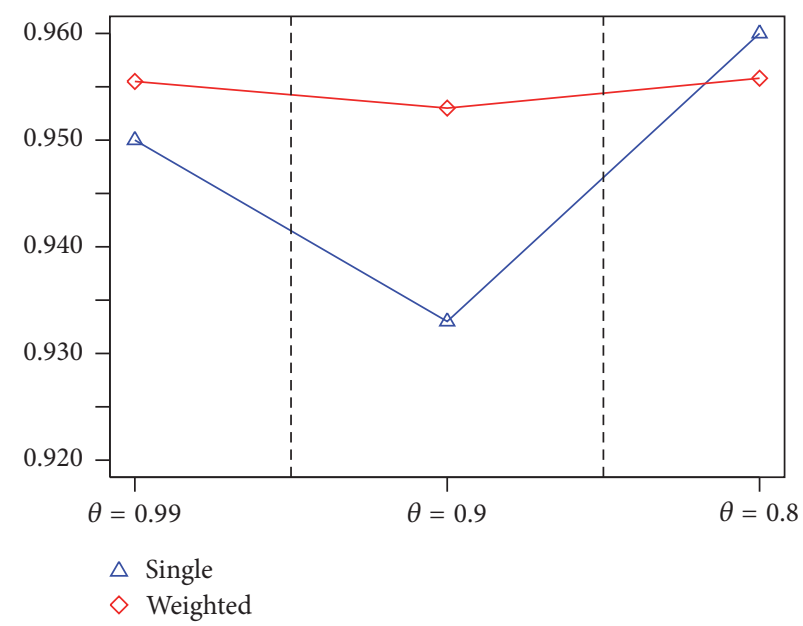

FIGURE 8: Comparison of maximum membership values.

$C_{t}$ : Inventory level of manufacturer over $t$ period

$S_{t}$ : Stock shortage of manufacturer over $t$ period

$\theta_{t}$ : Service level of the manufacturer over $t$ period

$M$ : An infinite number.

\section{Decision Variables}

$x_{i t}$ : Purchasing quantity from supplier $i$ over $t$ period

$y_{i t}: y_{i t}=1$ if a manufacturer places orders to suppliers $i$ over $t$ period, 0 otherwise.

\section{Competing Interests}

The authors declare that there is no conflict of interests regarding the publication of this paper.

\section{Acknowledgments}

This research is supported by National Natural Science Foundation of China [no. 71201099], Innovation Program of Shanghai Municipal Education Commission [no. 14YZ111], Shanghai Young Eastern Scholar Programme [QD2015041], Shanghai Pu Jiang Program (no. 13PJC066), and Shanghai Youth Teacher Foundation (no. ZZshhs13021).

\section{References}

[1] G. W. Dickson, "An analysis of vendor selection systems and decision," Journal of Purchasing, vol. 2, no. 15, pp. 1377-1382, 1966.

[2] C. A. Weber, J. R. Current, and W. C. Benton, "Vendor selection criteria and methods," European Journal of Operational Research, vol. 50, no. 1, pp. 2-18, 1991.

[3] L. A. Zadeh, "Fuzzy sets," Information and Control, vol. 8, no. 3, pp. 338-353, 1965. 
[4] L. Qian, "Market-based supplier selection with price, delivery time, and service level dependent demand," International Journal of Production Economics, vol. 147, pp. 697-706, 2014.

[5] A. Singh, "Supplier evaluation and demand allocation among suppliers in a supply chain," Journal of Purchasing \& Supply Management, vol. 20, no. 3, pp. 167-176, 2014.

[6] L. Zhen, "Task assignment under uncertainty: stochastic programming and robust optimisation approaches," International Journal of Production Research, vol. 53, no. 5, pp. 1487-1502, 2015.

[7] M. Dong, D. Yang, and Y. Wang, "Optimal decisions in product modularity design using real option approach," Concurrent Engineering Research and Applications, vol. 18, no. 1, pp. 31-39, 2010.

[8] M. Kumar, P. Vrat, and R. Shankar, "A fuzzy goal programming approach for vendor selection problem in a supply chain," Computers \& Industrial Engineering, vol. 46, no. 1, pp. 69-85, 2004.

[9] P. Kumar, R. Shankar, and S. S. Yadav, "An integrated approach of analytic hierarchy process and fuzzy linear programming for supplier selection," International Journal of Operational Research, vol. 3, no. 6, pp. 614-631, 2008.

[10] A. H. I. Lee, "A fuzzy supplier selection model with the consideration of benefits, opportunities, costs and risks," Expert Systems with Applications, vol. 36, no. 2, pp. 2879-2893, 2009.

[11] A. Kokangul and Z. Susuz, "Integrated analytical hierarch process and mathematical programming to supplier selection problem with quantity discount," Applied Mathematical Modelling, vol. 33, no. 3, pp. 1417-1429, 2009.

[12] F. Mafakheri, M. Breton, and A. Ghoniem, "Supplier selectionorder allocation: a two-stage multiple criteria dynamic programming approach," International Journal of Production Economics, vol. 132, no. 1, pp. 52-57, 2011.

[13] K. Shaw, R. Shankar, S. S. Yadav, and L. S. Thakur, "Supplier selection using fuzzy AHP and fuzzy multi-objective linear programming for developing low carbon supply chain," Expert Systems with Applications, vol. 39, no. 9, pp. 8182-8192, 2012.

[14] D. Choudhary and R. Shankar, "A goal programming model for joint decision making of inventory lot-size, supplier selection and carrier selection," Computers \& Industrial Engineering, vol. 71, no. 1, pp. 1-9, 2014.

[15] A. K. Kar, "A hybrid group decision support system for supplier selection using analytic hierarchy process, fuzzy set theory and neural network," Journal of Computational Science, vol. 6, pp. 23-33, 2015.

[16] J. Scott, W. Ho, P. K. Dey, and S. Talluri, "A decision support system for supplier selection and order allocation in stochastic, multi-stakeholder and multi-criteria environments," International Journal of Production Economics, vol. 166, pp. 226-237, 2015.

[17] Y. Ye, D. Yang, Z. Jiang, and L. Tong, "A knowledge- and workflow-based system for supporting order fulfillment process in the build-to-order supply chains," in The Semantic Web-ASWC 2006: First Asian Semantic Web Conference, Beijing, China, September 3-7, 2006. Proceedings, vol. 4185 of Lecture Notes in Computer Science, pp. 711-724, Springer, Berlin, Germany, 2006.

[18] R. N. Tiwari, S. Dharmar, and J. R. Rao, "Fuzzy goal programming-an additive model," Fuzzy Sets \& Systems, vol. 24, no. 1, pp. 27-34, 1987.

[19] D. Yang and M. Dong, "A hybrid approach for modeling and solving product configuration problems," Concurrent Engineering Research and Applications, vol. 20, no. 1, pp. 31-42, 2012. 

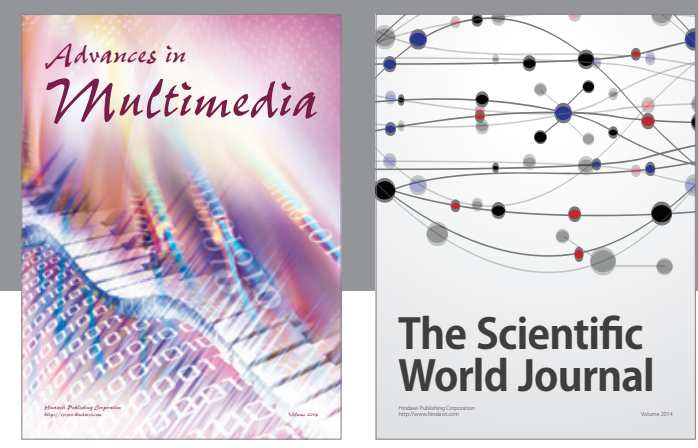

The Scientific World Journal
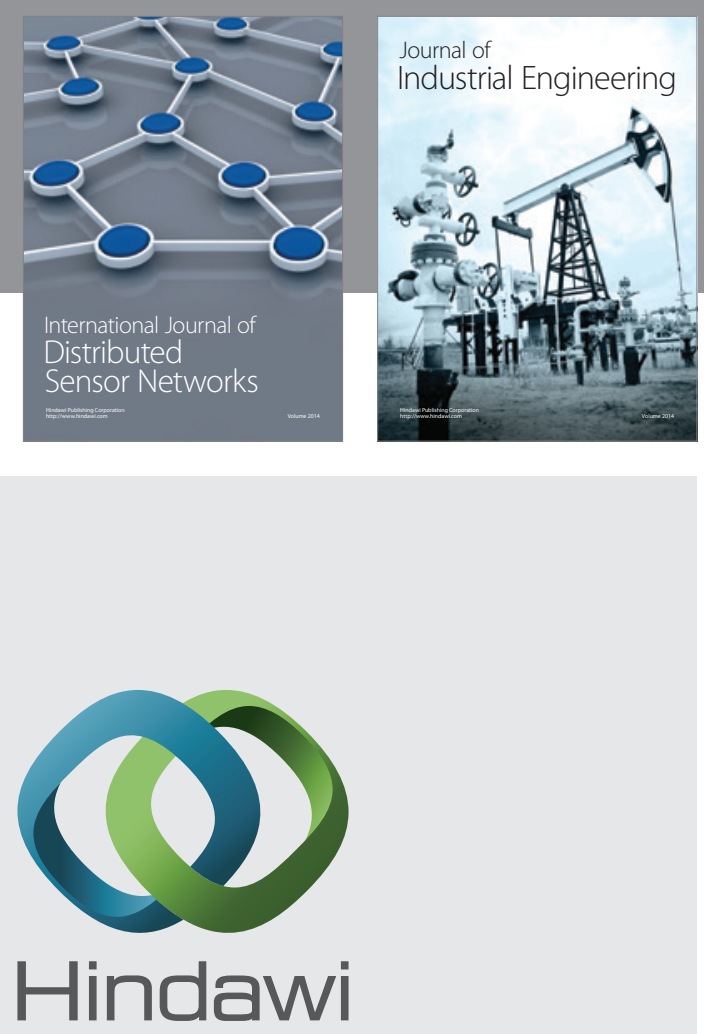

Submit your manuscripts at

http://www.hindawi.com

\section{Computer Networks} and Communications
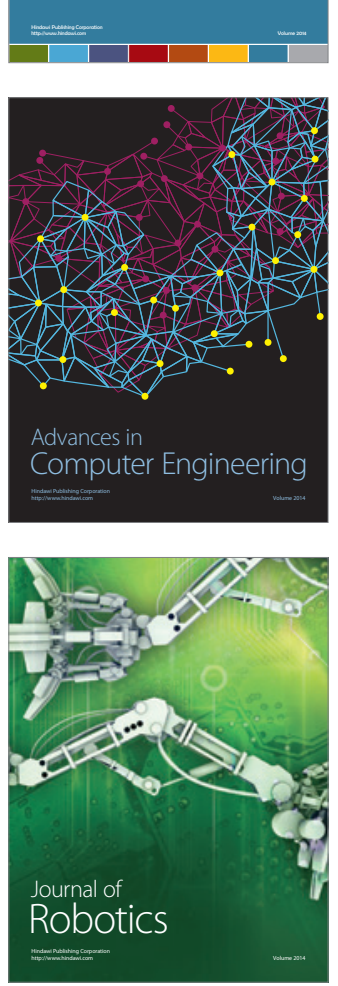
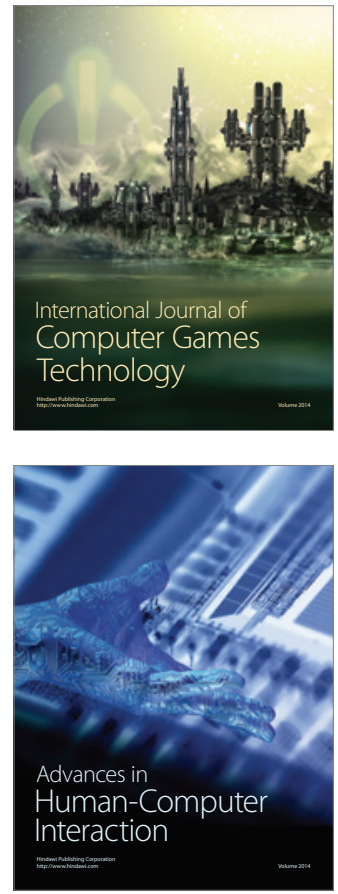
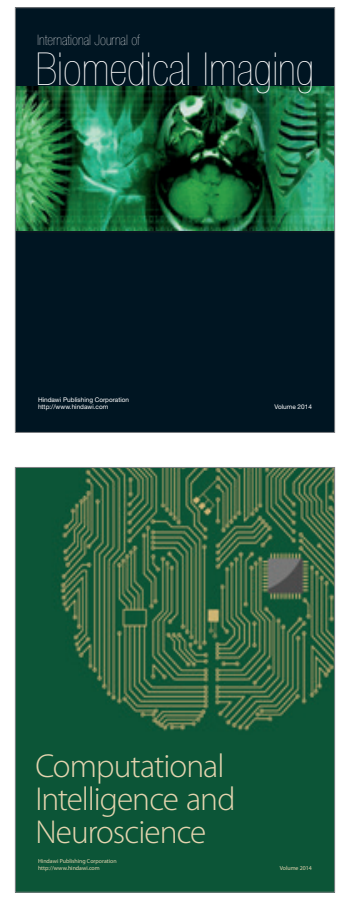
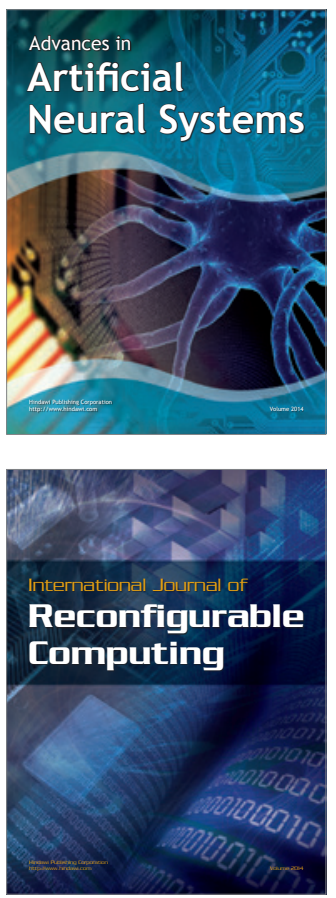
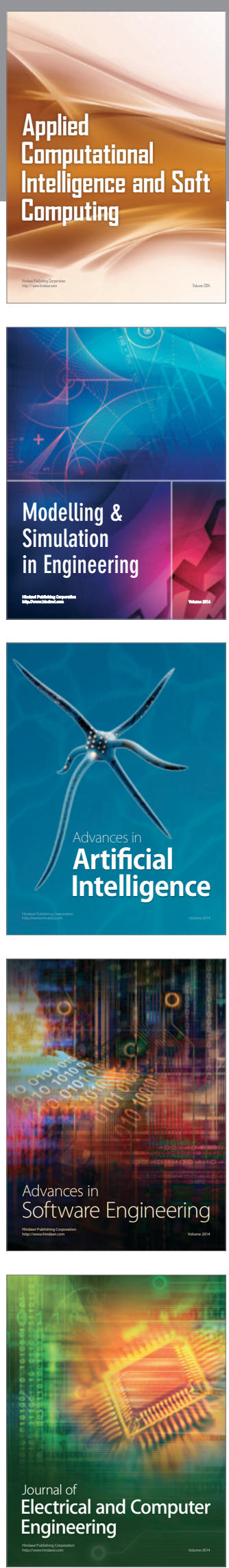